\title{
Anwendbarkeit eines polyklonalen Antiserums für den immunhistochemischen Nachweis von Pneumocystis carinii in bronchoalveolärer Lavage (BAL)
}

\section{Applicability of a Polyclonal Antiserum for the Immunohistochemical Detection of Pneumocystis carinii in Bronchoalveolar Lavage (BAL)}

\author{
A. Roth, K. Janitschke \\ Robert Koch-Institut des Bundesgesundheitsamtes Berlin, Fachgebiet Klinische Parasitologie (Direktor und Prof. Dr. K. Janitschke)
}

Die Diagnose einer Pneumocystis-carinii-Pneumonie wird durch den direkten Nachweis des Erregers in Patientenmaterial (überwiegend $\mathrm{BAL}$ ) mittels konventioneller Färbungen gestellt. Die Schaffung immunhistochemischer Nachweismethoden mit monoklonalen oder polyklonalen Antikörpern $(1-3)$ wurde angestrebt. Diese Techniken müssen weiter verbessert werden, um in der Laboratoriumsdiagnostik der Pneumocystose eingesetzt werden zu können.

Wir haben dieses Ziel weiterverfolgt. Menschliche infizierte Lunge wurde homogenisiert (Abb. $1 \mathrm{a}$ ), mit Pronase (Serva) inkubiert und in einer Saccharose-Gradientenzentrifugation aufgetrennt (3). Der 36\%-Gradient enthält am meisten Zysten und wurde $3 \mathrm{mal}$ mit PBS $\mathrm{pH}$ 7,2 gewaschen (Abb.1b). Es wurden 2 Kaninchen (Neu Seeländer) mit je 2 Mio. Zysten als gelöstes Antigen immunisiert (4mal alle 6 Tage eine Viertelportion mit Freudschem Adjuvans). Das Serum mit dem höchsten Titer (1:1280, 2 Wochen nach Immunisierung) wurde für den indirekten Immunfluoreszenztest (IIFT) verwendet (Serum 1:20 verdünnt; Konjugat: FITC Anti-Rabbit IgG $(H+L)$, Miles). Dafür wurde die BAL zunächst auch mit Pronase behandelt, danach $1 \mathrm{mal}$ (wie oben) gewaschen, auf Objektträger aufgetragen, luftgetrocknet und in $\mathrm{Me}$ thanol fixiert.

Die Zysten stellten sich typischerweise zusammengeballt ohne störende unspezifische Reaktionen als kräftig fluoreszierende ovale Gebilde dar (Abb. 2b). In einer Grocottgegenfärbung konnten die identischen Zysten nachgewiesen werden. Die Ergebnisse dieses IIFT korrelierten bei einer vorläufigen Untersuchung von $15 \mathrm{BAL}$ mit denen der Grocottfärbung. Eine leichte Kreuzreaktion mit Pilzen in nur einem Fall erschwerte die Beurteilung nicht, weil sie sich fluoreszenzoptisch viel schwächer und morphologisch anders darstellte (Hyphen!). Bemerkenswerterweise kommt die Antigen-Antikörper-Reaktion nur nach Inkubation des gesuchten Antigens mit Pronase zustande (Abb. 2a und b).

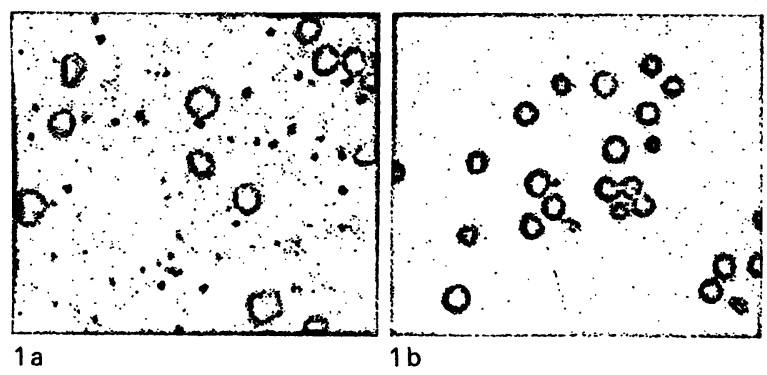

Abb. 1: Grocottfärbung, $580 \times$.a) Lungenhomogenat mit Zysten von $P$. carinii, b) daraus hergestelltes gereinigtes Antigen, mit dem immunisiert wurde, um das polyklonale Antiserum herzustellen (hier Silberimprägnierung zwecks Kontrasterhöhung für die Zählung stärker)
Die Extraktion der Zysten aus der Lunge gelingt ohne Anwendung von Enzymen nicht (4). Der Effekt der Pronase auf das Antigen ist als nachteilig beschrieben worden (4). Wir haben dieses Enzym in einer Minimalkonzentration angewandt, so daß Herstellung und Immunigenität des Antigens gewährleistet waren. Die enzymatische Behandlung des Untersuchungsmaterials verhindert einerseits unerwünschte Fluoreszenz, andererseits werden gesuchte Epitope der Erregeroberfläche günstig befreit oder biochemisch verändert, so daß der Antikörper das Antigen hochspezifisch wiedererkennt. Die vorläufigen Ergebnisse dieser Arbeit zeigen, daß dieses polyklonale Antiserum auf Grund dieser Enzymmethode durchaus mit monoklonalen Antikörpern konkurrieren kann. Wir sind dabei, diesen Immunfluoreszenztest mit Absorptionsversuchen und umfangreicherem Untersuchungsmaterial zu erproben und zu verbessern, um ihn in unserer Routinediagnostik einführen zu können.

Schriftum:

1. KOVACS, J. A., GILL, V., SWAN, J. C., OGNIBENE, F., SHELHAMER, J., PARILLO, J. E., MASUR, H.: Prospective evaluation of a monocional antibody in diagnosis of Pneumocystis carinii pneumonia. Lancet 2, 1-3 (1986).

2. GRAVES, D. C., McNABB, S. J. N., IVEY, M. H., WORLEY, M. A.: Development and characterization of monoclonal antibodies to Pneumocystis carinii. Infect. Immun. 51, $125-133$ (1986).

3. LIM. S. K., EVELAND, W. C., PORTER, R. J.: Direct fluorescent antibody method for the diagnosis of Pneumocystis carinii pneumonitis from sputa or tracheal aspirates from humans. Appl. Microb. 27, 144-149 (1974).

4. STAHR, B. J., WALZER, P. D., YONEDA, K.: Effect of proteolytic enzymes on Pneumocystis carinii in rat lung tissue. J. Parasitol. 67, 196-203 (1981).

Anschrift des Verfassers:

Andreas Roth

Robert-Koch-Institut

Fachgebiet Klinische Parasitologie

Nordufer 20

1000 Berlin 65

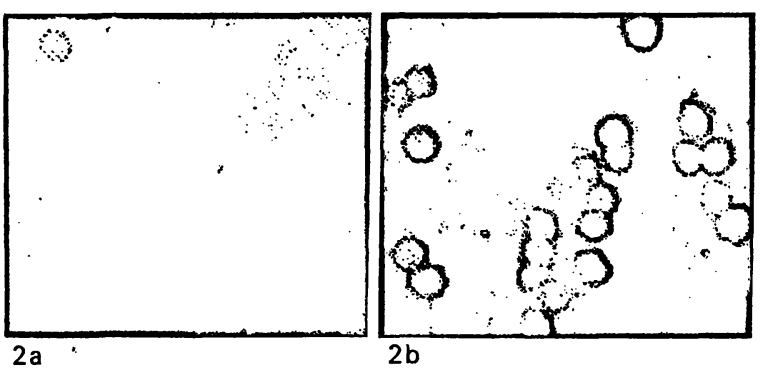

Abb. 2: IIFT mit polyklonalen Antikörpern, 580x. a) BAL ohne Pronase, im Präparat nur eine Zyste nachweisbar (links oben), unspezifische Fluoreszenz, b) die im selben Untersuchungsmaterial nach Pronaseinkubation entfällt. Die Zysten sind jetzt dargestellt 


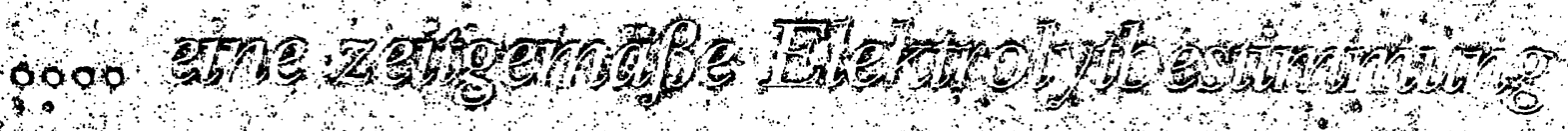
.

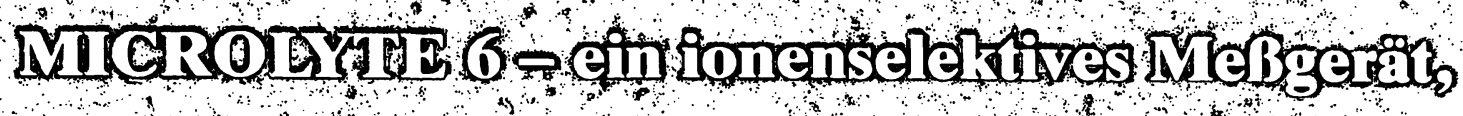

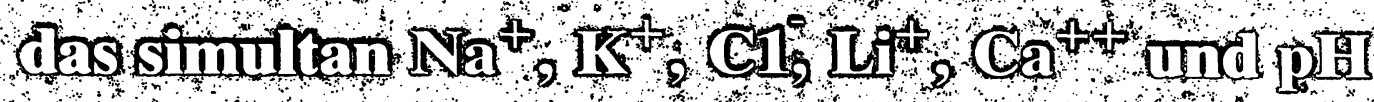

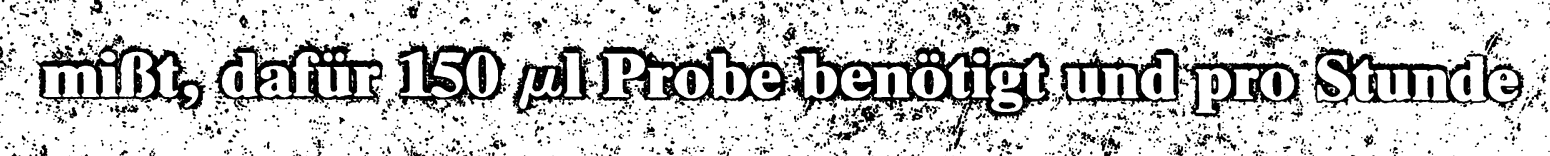

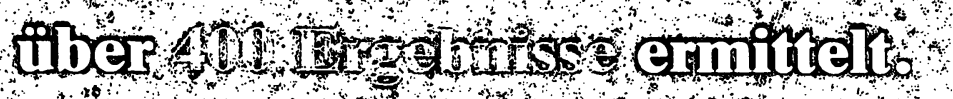

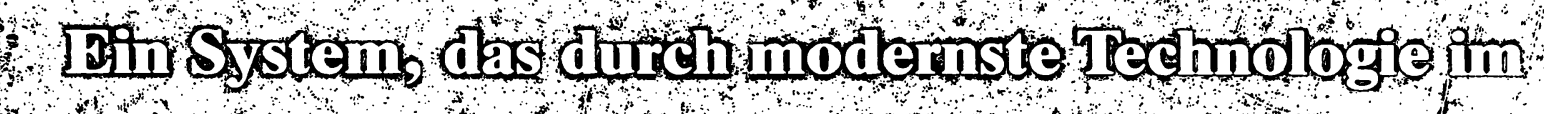

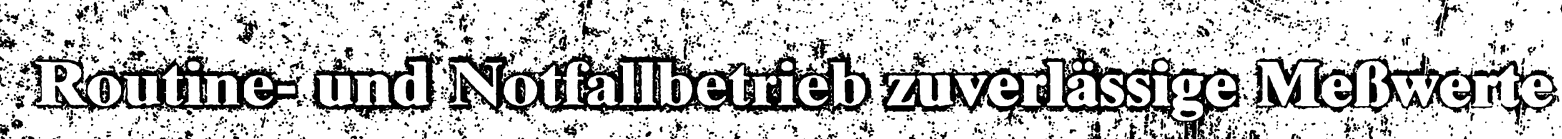
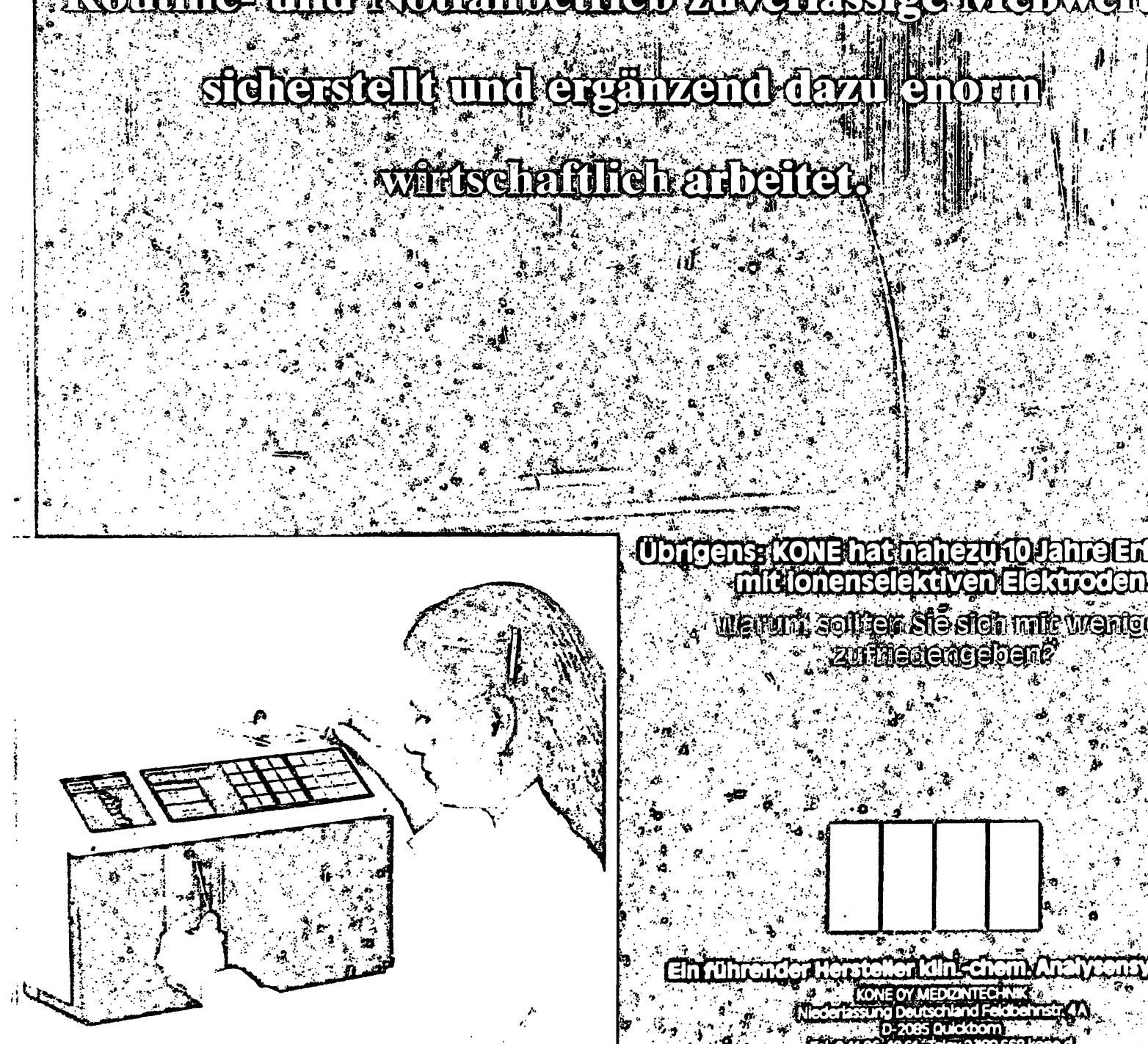

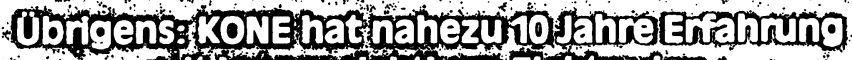

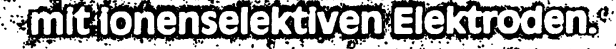

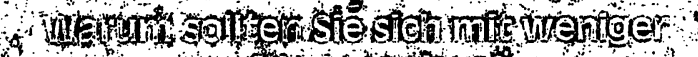

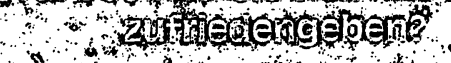




\section{Plexishilfen \\ Wissen, Tips und Service für den Arzt}

Herausgegeben von Frank H. Mader

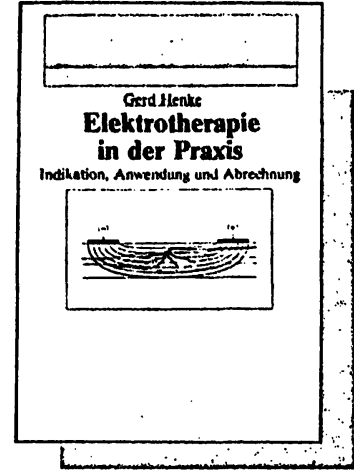

Indikation, Anwendung und $\mathrm{Ab}$ rechnung, 15 Tabellen und $37 \mathrm{Ab}$ bildungen, 80 Seiten, 3. Auflage, 24,80 DM.

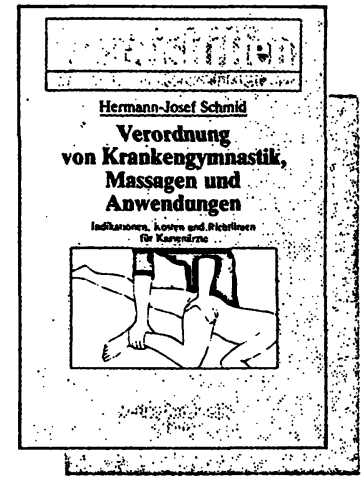

Indikationen, Kontraindikationen, Kosten und Richtlinien für Kassenärzte, 64 Seiten, 2. Auflage. 22,80 DM.

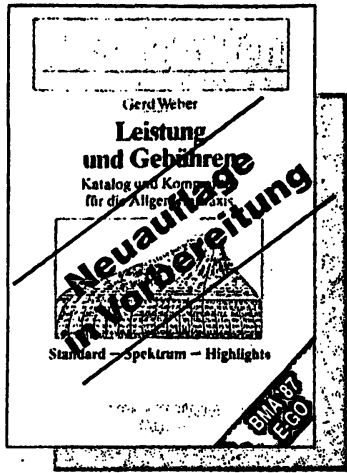

Katalog + Kommentar für die Allgemeinpraxis, gültig für BMÄ ' 87 und E-GO, 4. Auflage, $43,80 \mathrm{DM}$.

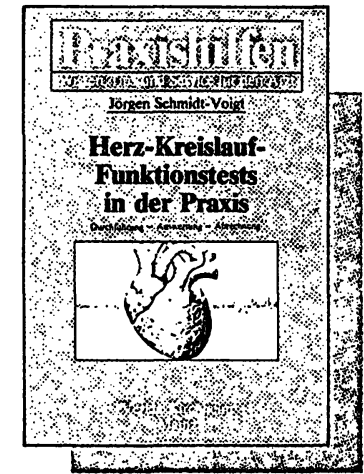

Durchführungen - Auswertung - Abrechnung, 17 Abbildungen, 56 Seiten, 3. Auflage, 24,80 DM.

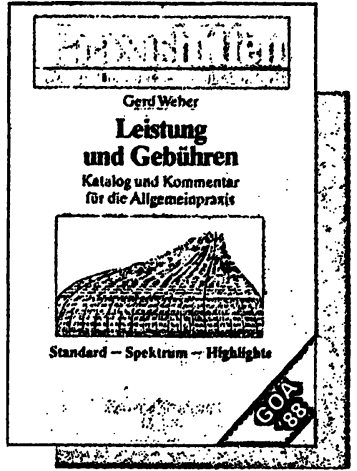

Katalog + Kommentar für die Allgemeinpraxis, GOÄ '88, Stand 1. 10. 88, 6. Auflage, 158 Seiten, 43,80 DM.

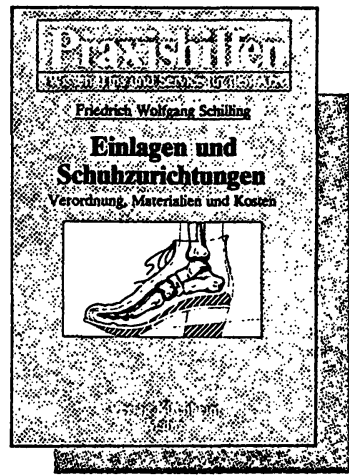

Ein Leitfaden für Verordnung, Materialien und Kosten, 44 Seiten, 2. Auflage, $24,80 \mathrm{DM}$.

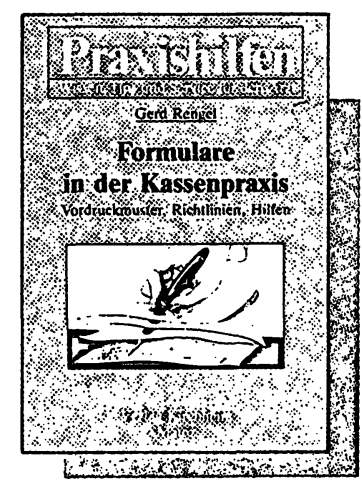

Vordruckmuster, Richtlinien und Hilfen, 102 Seiten, 49,80 DM.

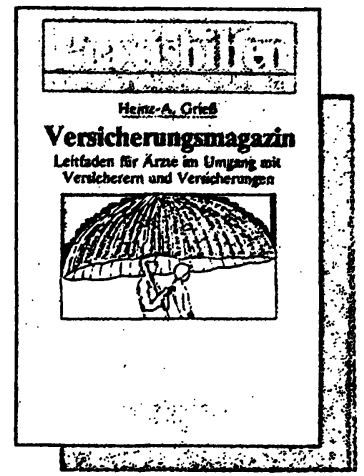

Leitfaden für Ärzte im Umgang mit Versicherern und Versicherungen, 24 Tabellen mit 12 ausklappbaren Seiten, 4 Abb., 52 Seiten, 3. Auflage, 22,80 DM.

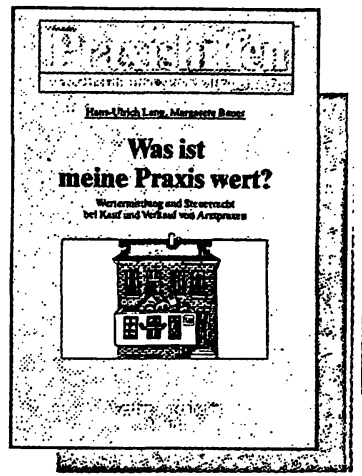

Wertermittlung und Steuerrecht bei Kauf und Verkauf von Arztpraxen, 50 Seiten, 25,80 DM.

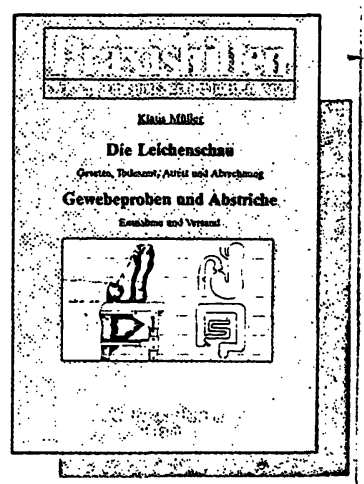

Gesetze, Todeszeit, Attest und Abrechnung, Gewebeproben und Abstriche, Entnahme und Versand, 52 Seiten, 25.80 DM.

Datum: Unterschrift: 